\title{
Study of Relationship Between Humor Styles and Attitude Toward Suicide with Psychological Well- Being in Teenagers
}

\author{
Narges Mirani Sargazi ${ }^{1}$, Mohadeseh Ordoni ${ }^{2}$, Mohammad Reza Dastamooz ${ }^{1}$, \\ Mohamadsadegh Besharatnia ${ }^{3,}$, Fatemeh Dehghan $^{4}$ \\ ${ }^{1}$ Educational Management, Faculty of Psychology and Educational Sciences, Shiraz University, Shiraz, Iran \\ ${ }^{2}$ Educational Psychology, Faculty of Psychology and Educational Sciences, Sistan and Baluchestan University, Zahedan, Iran \\ ${ }^{3}$ Curriculum Studies, Faculty of Psychology and Educational Sciences, Shiraz University, Shiraz, Iran \\ ${ }^{4}$ Educational Research, Payame Noor University of Shiraz, Shiraz, Iran
}

\section{Email address:}

M.besharat@gmail.com (M. Besharatnia)

*Corresponding author

\section{To cite this article:}

Narges Mirani Sargazi, Mohadeseh Ordoni, Mohammad Reza Dastamooz, Mohamadsadegh Besharatnia, Fatemeh Dehghan. Study of Relationship Between Humor Styles and Attitude Toward Suicide with Psychological Well- Being in Teenagers. International Journal of Psychological and Brain Sciences. Vol. 5, No. 6, 2020, pp.92-100. doi: 10.11648/j.jppb.20200506.12

Received: August 8, 2020; Accepted: August 26, 2020; Published: December 11, 2020

\begin{abstract}
The adolescence is considered a dangerous period for the suicide. In this period, the suicide commitment as a behavior sometimes is regarded as a solution for the mental and external conflicts. The suicide is of mental health problems. The researches done in the case of suicide study three crucial phenomena including suicidal thoughts, attempting suicide and suicide itself. The present research aims to study the relationship between the humor styles and attitude toward suicide with the psychological well- being in the teenagers. Descriptive- surveying method has been applied in this study. The statistic population of present study includes all the male and female teenagers of Zahedan city during the school year 2018- 19. The studied sample was selected by random sampling and Cochran formula that its volume was equal to 270 members. The tools used for collecting data were the questionnaires including Martin and his colleagues' questionnaire (1998) and Multi-Attitude Suicide Tendency Scale (MAST) questionnaire presented by Orbach and his colleagues. SPSS25 software was used for analyzing the data. According to the descriptive statistics of the data, among the dimensions of humor styles and dimensions of attitude toward suicide, the most average is related to the self- defeating style and the affiliative style, respectively. The results of data analysis confirmed all the existing hypotheses and revealed that there is relationship between the humor styles and the attitude toward suicide with the psychological well- being in the teenagers.
\end{abstract}

Keywords: Low Humor, Suicide, Psychological Well-Being

\section{Introduction}

\subsection{Introduce the Problem}

Nowadays, the individuals make their maximum effort to access a comfortable and appropriate life. In such situations in which the human being encounters constantly to the economic developments and social revolutions, there exist many individuals who suffer the mental problems such as stress, anxiety and other emotional problems which are resulted in losing the tolerance and self- confidence in some of them.
Ultimately, these individuals try to leave their life because of severity of social and mental pressures and commit the suicide [1].

According to the World Health Organization, every year almost one million people die by suicide around the world, and it is the second leading cause of death in the 15 to 19 years age group [2]. Suicide is one of the leading causes of death worldwide [3]. Approximately 800,000 persons die from 
suicide each year, which is more than one suicide per minute [2]. According to Akotia et al [4], the reasons of suicide attempting include:

1) lack of support; 2) abandonment; 3 ) shame; 4) existential struggles; and 5) supernatural reasons.

Suicide ideation is a multifaceted issue that involves bio-psychosocial and cultural factors. As Park [5] pointed out, suicidal ideation precedes suicidal acts, so the identification of predictors of ideation might lead to a better understanding of suicide risk, and it may help to prevent suicide [5].

If the teenager attempt the suicide, there are always the cultural shackles for encountering that. The learning theory emphasizes the individual's reactions in the etiology of suicidal behavior [6]

Enhanced psychological resilience may help to reduce the incidence of suicide ideation in adolescents [7]. The humor and its different styles is the other phenomenon which has recently attracted the attention of many individuals and is not unrelated to the research variables. The humor is a coping strategy against the tension which is regarded as a mechanism against the anxiety and is expressed as a method for solving the life difficulties. Indeed, it is a survival skill for distancing from a problem [8]. The humor styles were introduced for the first time by Martin [9]. He has categorized that into four styles: 1- self- enhancing style, 2- affiliative style, 3aggressive style, 4- self- defeating style. The researches indicate that the adaptive humor correlates with the mental health [10]. the humor has positive consequences of which it can be referred to the contentment, satisfaction, compatibility with physical inabilities, satisfaction with life, encountering with the stress and the individual's protection against diseases such as cancer and suicide prevention. The people require a meaningful life, they don't want to awake with a sense of depression and live their lifetime with irritation and disturbance. The historical evidence and daily life experience indicate that the most salient human attitudes is the access to the welfare and happiness [11].

Factors such as material deprivation, family financial strain, parental well-being and experience of being bullied emerge as important in the analysis [12]. Physical and psychosocial changes during adolescence could influence the psychological well-being.

\subsection{Explore Importance of the Problem}

With regard to the positive aspects of psychological health, the concept of psychological well- being is a multi- element concept including the self- acceptance and positive relation with others, self- autonomy, environmental mastery, purposeful life and personal growth that special attention has been paid to that and positive mental health in recent decades. Riff's model is one of most important models in the psychological well- being. Riff considers the psychological well- being as an effort for the fulfillment of the individual's potential real abilities [28].

Armsden and Greenberg [29] used self-esteem, life satisfaction and affect status to indicate adolescents'psychological well-being; Shek [13] examined hopelessness, purpose in life and general psychiatric morbidity in addition to life satisfaction and self-esteem in a series of studies about psychological well-being of adolescents. The effects of a peer's suicide on adolescents' mental health problems and suicide risk has been the focus of myriad studies. The majority of cross-sectional analyses examining adolescents' exposure to a peer's suicidal behavior have found a significant association with adolescent suicidal ideation and attempts [14, 15]. examined hopelessness, purpose in life and general psychiatric morbidity in addition to life satisfaction and self-esteem in a series of studies about psychological well-being of adolescents. Some other indicators have also been adopted, such as mental health, hope, anxiety and depression [16-18]. Much research has been done on these variables [19-26].

But the relationship between these three variables has been studied in no research in this form. It is obvious that the prevention or treatment approaches can have positive effects on the individuals' psychological well- being. With regard to the studies done in the case of suicide, the life of human beings is changed and the suicide has been increased in comparison to the past years. The number of teenagers' suicides has been three- to four- fold during the past [27]. Regarding what was said, because the adolescence is the period of severe crises and involves different challenges, so it requires specific cares in the social environment and family. If the humor elements in the teenagers and their attitude toward suicide be recognized, it can be expected that their mental health and psychological well- being would be positively improved, they would easily encounter the crisis of this period and balance their life as possible.

A lack of systematic approach to investigating psychological well-being may be due to the absence of sound theoretical framework of psychological well-being in adolescent studies.

So, the recognition of factors effective on suicide would help the healers to take required measures in their clinical services in the control of these factors. On the other side, increase of amount of suicide among this group of people reveals the necessity of such researches. In this respect, the present research aims to answer this question that is there relationship between the humor styles and attitude toward suicide with the psychological well- being among the teenagers?

\subsection{State Hypotheses and Their Correspondence to Research Design}

The problem with this research can be summed up in the following hypotheses:

There is a relationship between attitude styles and suicide and humor jokes and psychological well-being.

Humorous styles can predict suicidal ideation.

Humorous styles predict psychological well-being.

The dimensions of psychological well-being predict a suicidal attitude 


\section{Method}

The present research is a descriptive- surveying applied study that is based on the recognition of relationship between the variables. The statistic population of present research includes all the 15 to 17 years old teenagers (male and female) in Zahedan city during the school year 2018- 19.

\subsection{Participant (Subject) Characteristics}

Adolescent selection was not based on specific input criteria based on gender. All stages of the study were discussed with the parents of the adolescents, and those who wished to have their child participate in the study signed a conscious consent before the study began..

\subsection{Sampling Procedures}

At first, from among three districts of Zahedan city, district 1 and from among nine regions of this city, region 1 were selected by cluster random sampling. Then, from among the secondary schools of mentioned region, 9 schools were randomly selected. Three classed were selected from every school and, regarding the majors existing in secondary school, 10 students were randomly selected. With regard to the aforesaid calculations, the research sample includes 270 male and female teenager students (junior and senior) from among all the majors (experimental sciences, mathematics and human sciences) that are educating during the school year 2018- 19 in the region 1 of education department in Zahedan city. The sample includes 270 students of secondary schools. From among them, 144 and 126 students are female and male, respectively. 89,98 , and 83 students respectively are 15, 16, and 17 years old. In this study, Martin and his colleagues' (1988) humor styles standard questionnaire, multi- attitude suicide tendency scale (MAST) and Ryff [33] psychological well- being scale were used as tools for collecting data from the selected sample..

\subsection{Measures and Covariates}

1. Ryff Psychological Welfare Scal [33]: The 18-page short version of the Reef Psychological Welfare Scale was designed by Reef in 1989 and revised in 2002. This questionnaire has 18 questions and its purpose is to evaluate and evaluate psychological well-being from various dimensions including: independence, mastery. It is about the environment, personal growth, positive communication with others, purposefulness in life, self-acceptance. The correlation of the short version of the Rif psychological well-being scale with the main scale varies from $0.7-0.89$. In general, by juxtaposing the results of various studies, it can be concluded that Form 18 of the Welfare Question has a high internal validity and similarity. Its scoring range is based on the six-choice Likert range.

2. Martin and his colleagues' [34] humor styles standard questionnaire: The Joke Styles Questionnaire was designed by [34] This questionnaire has 32 items and 4 factors. Identify each item in the five-part Likert range from very low (score 1) to very high (score 5).

Humor styles: Humor is a positive and inclusive activity that people from social and cultural backgrounds around the world experience. The term refers to a quality of action, speech, writing that entertains and entertains. Humor is defined as a person's habitual differences in behaviors, experiences, emotions, attitudes, and ability to engage in entertainment, laughter, joking, and so on.

Operational Definition of Variable Questionnaire: In this study, humor means a score that the respondents give to the 32-item questions of humor.

Validity or validity deals with the extent to which a measuring instrument measures what we think [30]. In the research [31] the validity of the questionnaire has been confirmed by professors and experts in this field. The questionnaire is scored in the range of 5 point Likert

3. Multi- attitude suicide tendency scale (MAST): MAST Suicide Scale (MAST) was developed by Orbach and et al [32] with 30 items and 4 subscales of life attraction, non-acceptance of life, attraction of death, and The non-acceptance of death is formed to measure adolescent suicidal ideation.

Operational definition: In this study, the standard score for suicidal ideation is the score that a person gives to a 30 -item questionnaire of Orbach et al.

In Orbach's research, the instrument has a good internal consistency with an alpha coefficient ranging from 0.76 (for non-acceptance of life and attraction of death) to 0.83 (for attraction of life and non-acceptance of death).

This tool has a good validity with a significant correlation between the scales of life attraction (negative) and non-acceptance of life and death attraction (positive) and the suicide risk index. Also, due to the significant differences between the three groups of healthy, suicidal tendencies and mental patients, this tool has a relatively good narrative by comparing it with the known groups as follows: In terms of life attraction, the normal group score was higher than the two groups. In the case of non-acceptance of life, all 3 groups were different, the highest scores were in the suicidal group and the lowest scores were in the normal group; and in the case of death attraction, the suicidal group was the highest.

The questionnaire is scored in the range of 5 point Likert

\section{Results}

The present research aimed to study the relationship between the humor styles and attitude toward suicide with the psychological well- being in the teenagers of Zahedan city during the school year 2018-19. The results of present study are as following:

Statistics and Data Analysis

Data analysis was performed using descriptive and inferential statistics using spss25 software.

Statistics and Data Analysis 
Table 1. Matrix of correlation between research variables.

\begin{tabular}{|c|c|c|c|c|c|c|c|}
\hline & 1 & 2 & 3 & 4 & 5 & 6 & 7 \\
\hline 1. attitude toward suicide & 1 & & & & & & \\
\hline 2. life attraction & $-0.90 * *$ & 1 & & & & & \\
\hline 3. life non- acceptance & $0.75^{* *}$ & $-0.84 * *$ & 1 & & & & \\
\hline 4. death attraction & $0.80 * *$ & $-0.81 * *$ & $0.68 * *$ & 1 & & & \\
\hline 5. death non- acceptance & $-0.89 * *$ & $0.81 * *$ & $-.69 * *$ & $-0.72 * *$ & 1 & & \\
\hline 6. affiliative style & $-0.25 * *$ & $0.34 * *$ & $-0.27 * *$ & $-0.31 * *$ & $0.26^{* *}$ & 1 & \\
\hline 7. self- enhancing style & $-0.24 * *$ & $0.26^{* *}$ & $-0.27 * *$ & $-0.30 * *$ & $0.24 * *$ & $0.89 * *$ & 1 \\
\hline 8. aggressive style & $0.26^{* *}$ & $-0.29 * *$ & $0.18^{* *}$ & $0.28 * *$ & $-0.19 * *$ & $-0.85 * *$ & $-0.80 * *$ \\
\hline 9. self- defeating style & $0.27 * *$ & $-0.34 * *$ & $0.24 * *$ & $0.30 * *$ & $-0.25 * *$ & $-0.84 * *$ & $-0.92 * *$ \\
\hline 10. psychological well- being & $-0.34 * *$ & $0.42 * *$ & $-0.32 * *$ & $-0.35 * *$ & $0.24 * *$ & $0.34^{* *}$ & $0.38^{* *}$ \\
\hline 11. autonomy & -0.01 & 0.10 & -0.04 & -.0 .010 & -0.05 & $0.20^{* *}$ & $0.20^{* *}$ \\
\hline 12. environmental mastery & -0.01 & 0.06 & -0.03 & -0.10 & -0.07 & $0.15 *$ & $0.16^{* *}$ \\
\hline 13. personal growth & -0.03 & -0.06 & 0.08 & 0.04 & 0.06 & $-0.13 *$ & $-0.15^{*}$ \\
\hline 14. positive relation with others & $-0.52 * *$ & $0.60^{* *}$ & $-0.52 * *$ & $-0.43 * *$ & $0.48^{* *}$ & $0.31 * *$ & $0.37 * *$ \\
\hline 15. purposefulness in life & $-0.26 * *$ & $0.31^{* *}$ & $-0.26 * *$ & $-0.24 * *$ & $0.22 * *$ & $0.30 * *$ & $0.35^{* *}$ \\
\hline 16. self- acceptance & -0.06 & 0.10 & -0.02 & -0.09 & -0.5 & 0.02 & 0.04 \\
\hline Mean & 4.02 & 3.07 & 3.32 & 3.30 & 2.97 & 3.40 & 3.42 \\
\hline Standard deviation & 0.78 & 1.57 & 1.53 & 1.53 & 1.52 & 1.79 & 1.78 \\
\hline Kurtosis & -1.33 & -1.58 & -1.57 & -1.50 & -1.24 & -1.33 & -1.50 \\
\hline Skewness & -0.291 & 0.225 & -0.033 & -0.028 & 0.493 & 0.277 & 0.182 \\
\hline
\end{tabular}

Table 1. Continued.

\begin{tabular}{|c|c|c|c|c|c|c|c|c|c|}
\hline & 8 & 9 & 10 & 11 & 12 & 13 & 14 & 15 & 16 \\
\hline \multicolumn{10}{|l|}{ 1. attitude toward suicide } \\
\hline \multicolumn{10}{|l|}{ 2. life attraction } \\
\hline \multicolumn{10}{|l|}{ 3. life non- acceptance } \\
\hline \multicolumn{10}{|l|}{ 4. death attraction } \\
\hline \multicolumn{10}{|l|}{ 5. death non- acceptance } \\
\hline \multicolumn{10}{|l|}{ 6. affiliative style } \\
\hline \multicolumn{10}{|l|}{ 7. self- enhancing style } \\
\hline 8. aggressive style & 1 & & & & & & & & \\
\hline 9. self- defeating style & $-0.84^{* *}$ & 1 & & & & & & & \\
\hline 10. psychological well- being & $-0.35^{* *}$ & $-0.38^{* *}$ & 1 & & & & & & \\
\hline 11. autonomy & $-0.23 * *$ & $-0.23 * *$ & $0.65^{* *}$ & 1 & & & & & \\
\hline 12. environmental mastery & $-0.18 * *$ & $-0.20 * *$ & $0.54 * *$ & $0.46^{* *}$ & 1 & & & & \\
\hline 13. personal growth & $0.14 *$ & $0.14 *$ & $-0.23 * *$ & $-0.43 * *$ & $-0.49 * *$ & 1 & & & \\
\hline 14. positive relation with others & $-0.26^{* *}$ & $-0.32 * *$ & $0.51^{* *}$ & 0.03 & -0.04 & 0.03 & 1 & & \\
\hline 15. purposefulness in life & $-0.32 * *$ & $-0.34 * *$ & $0.68 * *$ & $0.41 * *$ & $0.36^{* *}$ & $-0.39 * *$ & $0.24 * *$ & 1 & \\
\hline 16. self- acceptance & -0.02 & -0.03 & $0.45 * *$ & $0.18 * *$ & $0.12 * *$ & $-0.24 * *$ & 0.02 & $0.12 *$ & 1 \\
\hline Mean & 4.87 & 4.72 & 2.89 & 2.76 & 3.06 & 3.33 & 2.70 & 2.89 & 2.59 \\
\hline Standard deviation & 1.53 & 1.59 & 0.54 & 1.28 & 1.16 & 1.12 & 1.29 & 1.25 & 1.18 \\
\hline Kurtosis & -1.17 & -1.25 & -0.67 & -1.53 & -1.30 & -1.04 & -1.43 & -1.44 & -1.28 \\
\hline Skewness & -0.332 & -0.281 & 0.140 & 0.224 & -0.154 & -0.265 & 0.279 & 0.095 & 0.309 \\
\hline
\end{tabular}

** Significance at the level of 0.01 .

* Significance at the level of 0.05 .

The results of table 1 indicate that the relationship between attitude toward suicide and two dimensions of life nonacceptance and death attraction with the affiliative style and self- enhancing is negative and their relationship with two aggressive and self- defeating styles is positive $(\mathrm{P} \leq 0.05)$; while the findings reveal that two dimensions of life attraction and death non- acceptance have positive relationship with two affiliative and self- enhancing styles and negative and reverse relationship with two aggressive and self- defeating styles $(\mathrm{P} \leq 0.05)$. Furthermore, the study of relationship between the psychological well- being and two elements of positive relation with others and purposefulness in life have negative relationship with the attitude toward suicide and two dimensions of life non- acceptance and death attraction and have positive relationship with two dimensions of life attraction and death non- acceptance $(\mathrm{P} \leq 0.05)$. However, the findings revealed no meaningful relationship between the elements of autonomy, environmental mastery, personal growth and selfacceptance with the attitude toward suicide and its dimensions $(\mathrm{P}>0.05)$. In addition, the results obtained from the study of relationship between the psychological well- being and its elements with the humor styles show that the psychological well- being, autonomy, environmental mastery, positive relation with others and purposefulness in life have positive 
relationship with two affiliative and self- enhancing styles and negative relationship with two aggressive and self- defeating styles $(\mathrm{P} \leq 0.05)$. While the results reveal the negative relationship between the personal growth with two affiliative and self- enhancing styles, its relationship with two aggressive and self- defeating styles is positive $(\mathrm{P} \leq 0.05)$. But there has been observed no meaningful relationship between the element of self- acceptance with the attitude toward suicide and its dimensions $(\mathrm{P}>0.05)$. Furthermore, the findings of descriptive statistic indicate that the mean of attitude toward suicide, psychological well- being, affiliative style, self- enhancing style, aggressive style and self- defeating style is respectively 4.03 , $2.89,3.40,3.42,4.87$ and 4.72 . In addition, the kurtosis and skewness indexes were used for evaluating the normality of data. As it is observed in table 1, the amount of skewness and kurtosis observed for all the variables is between -2 and +2 ; it indicates that the studied variables are normal in terms of skewness and kurtosis and their distribution is symmetrical.

Table 2. Summary of multi-regression coefficients of attitude toward suicide and its dimensions based on humor styles.

\begin{tabular}{|c|c|c|c|c|c|c|c|c|c|}
\hline Criterion variable & Predictor variable & $\boldsymbol{\beta}$ & Beta & $\mathbf{t}$ & p-value & $\mathbf{R}$ & $\mathbf{R}^{2}$ & $\mathbf{F}$ & p-value \\
\hline \multirow{5}{*}{ Life attraction } & Fixed & 1.974 & & 1.663 & 0.098 & \multirow{5}{*}{0.363} & \multirow{5}{*}{0.132} & \multirow{5}{*}{10.084} & \multirow{5}{*}{0.000} \\
\hline & Affiliative style & 0.160 & 0.183 & 1.272 & 0.204 & & & & \\
\hline & Self- enhancing style & 0.157 & 0.178 & 1.037 & 0.301 & & & & \\
\hline & Aggressive style & 0.097 & 0.095 & 0.787 & 0.432 & & & & \\
\hline & Self- defeating style & -0.096 & -0.098 & -0.622 & 0.535 & & & & \\
\hline \multirow{4}{*}{ Life non- acceptance } & Fixed & 5.164 & & 4.339 & 0.000 & \multirow{4}{*}{0.293} & \multirow{4}{*}{0.086} & \multirow{4}{*}{6.208} & \multirow{4}{*}{0.000} \\
\hline & Self- enhancing style & -0.116 & -0.135 & -0.765 & 0.445 & & & & \\
\hline & Aggressive style & -0.196 & -0.196 & -1.585 & 0.114 & & & & \\
\hline & Self- defeating style & 0.058 & 0.061 & 0.375 & 0.708 & & & & \\
\hline \multirow{4}{*}{ Death attraction } & Fixed & 3.565 & & 3.033 & 0.003 & \multirow{4}{*}{0.320} & \multirow{4}{*}{0.103} & \multirow{4}{*}{7.569} & \multirow{4}{*}{0.000} \\
\hline & Affiliative style & -0.165 & -0.194 & -1.325 & 0.186 & & & & \\
\hline & Self- enhancing style & -0.039 & -0.045 & -0.258 & 0.797 & & & & \\
\hline & Aggressive style & -0.002 & 0.002 & -0.014 & 0.989 & & & & \\
\hline \multirow{5}{*}{ Death non- acceptance } & Fixed & 2.775 & & 2.348 & 0.020 & \multirow{5}{*}{0.291} & \multirow{5}{*}{0.085} & \multirow{5}{*}{6.116} & \multirow{5}{*}{0.000} \\
\hline & Affiliative style & 0.298 & 0.352 & 2.383 & 0.018 & & & & \\
\hline & Self- enhancing style & -0.152 & -0.178 & -1.006 & 0.315 & & & & \\
\hline & Aggressive style & 0.209 & 0.210 & 1.698 & 0.091 & & & & \\
\hline & Self- defeating style & -0.279 & -0.293 & -1.809 & 0.072 & & & & \\
\hline \multirow{5}{*}{$\begin{array}{l}\text { Total score of attitude } \\
\text { toward suicide }\end{array}$} & Fixed & 3.108 & & 5.116 & 0.000 & \multirow{5}{*}{0.287} & \multirow{5}{*}{0.082} & \multirow{5}{*}{0.940} & \multirow{5}{*}{0.000} \\
\hline & Affiliative style & 0.059 & -0.135 & -0.915 & 0.361 & & & & \\
\hline & Self- enhancing style & 0.087 & 0.199 & 1.125 & 0.262 & & & & \\
\hline & Aggressive style & 0.023 & 0.044 & 0.358 & 0.721 & & & & \\
\hline & Self- defeating style & 0.149 & 0.306 & 1.883 & 0.061 & & & & \\
\hline
\end{tabular}

According to the results presented in table 2, it can be said that at all the levels of studying the relationships between the humor styles and its attitude toward suicide and its dimensions, from among the humor styles, only the affiliative style can predict the dimension of death non- acceptance $(\mathrm{P} \leq 0.05 ; \mathrm{t} \geq$ 1.96), but at the other levels of studying the relationships, the results indicate that the humor styles cannot predict the attitude toward suicide and the dimensions of death attraction, life non- acceptance and death attraction $(\mathrm{P}>0.05 ; \mathrm{t}<1.96)$.

The results of multi- regression analysis show that the affiliative style with regression coefficient 0.29 specifies about 9 percent of the death non- acceptance variance.

Table 3. Summary of linear sample regression coefficients of humor styles based on psychological well- being.

\begin{tabular}{lllllll}
\hline Predictor variable & Criterion variable & B & R & R $^{\mathbf{2}}$ & t & p- value \\
\hline & Affiliative style & 1.132 & 0.339 & 0.115 & 5.894 & 34.744 \\
Psychological well- & Self- enhancing style & 1.255 & 0.379 & 0.144 & 6.712 & 45.050 \\
being & Aggressive style & -0.982 & 0.345 & 0.119 & -6.022 & 36.263 \\
& Self- defeating style & -1.129 & 0.380 & 0.144 & -6.726 & 45.239 \\
\hline
\end{tabular}

As it is observed in table 3, the effect of psychological wellbeing on all four humor styles is meaningful. According to the findings, the effect of well- being on two affiliative and selfenhancing styles is positive and its effect on two aggressive and self- defeating styles is reverse (negative) $(\mathrm{P} \leq 0.05 ; \mathrm{t} \geq$
1.96); in such a way that it can be said: the psychological wellbeing with regression coefficients $0.40,0.38,0.35$ and 0.38 respectively specifies $12,14,12$ and 14 percent of the variance of affiliative, self- enhancing, aggressive and self- defeating styles. 
Table 4. Summary of multi-regression coefficients of humor styles based on dimensions of psychological well-being.

\begin{tabular}{|c|c|c|c|c|c|c|c|c|c|}
\hline Criterion variable & Predictor variable & $\boldsymbol{\beta}$ & Beta & $\mathbf{T}$ & p-value & $\mathbf{R}$ & $\mathbf{R}^{2}$ & $\mathbf{F}$ & p-value \\
\hline \multirow{7}{*}{ Affiliative style } & Fixed & 1.143 & & 1.545 & 0.123 & \multirow{7}{*}{0.406} & \multirow{7}{*}{0.165} & \multirow{7}{*}{8.666} & \multirow{7}{*}{0.000} \\
\hline & Autonomy & 0.150 & 0.107 & 1.569 & 0.118 & & & & \\
\hline & Environmental mastery & 0.077 & 0.049 & 0.716 & 0.475 & & & & \\
\hline & Personal growth & -0.007 & -0.004 & -0.060 & 0.952 & & & & \\
\hline & Positive relation with others & 0.378 & 0.271 & 4.617 & 0.000 & & & & \\
\hline & Purposefulness in life & 0.249 & 0.173 & 2.082 & 0.010 & & & & \\
\hline & Self- acceptance & -0.043 & -0.028 & -0.481 & 0.631 & & & & \\
\hline \multirow{7}{*}{ Self- enhancing style } & Fixed & 1.028 & & 1.451 & 0.148 & \multirow{7}{*}{0.467} & \multirow{7}{*}{0.218} & \multirow{7}{*}{12.246} & \multirow{7}{*}{0.000} \\
\hline & Autonomy & 0.097 & 0.070 & 1.064 & 0.288 & & & & \\
\hline & Environmental mastery & 0.076 & 0.049 & 0.739 & 0.461 & & & & \\
\hline & Personal growth & -0.035 & -0.022 & -0.328 & 0.743 & & & & \\
\hline & Positive relation with others & 0.433 & 0.314 & 5.518 & 0.000 & & & & \\
\hline & Purposefulness in life & 0.321 & 0.225 & 3.477 & 0.001 & & & & \\
\hline & Self- acceptance & -0.032 & -0.021 & -0.277 & 0.707 & & & & \\
\hline \multirow{6}{*}{ Aggressive style } & Autonomy & -0.147 & -0.123 & -1.808 & 0.072 & \multirow{6}{*}{0.402} & \multirow{6}{*}{0.161} & \multirow{6}{*}{8.430} & \multirow{6}{*}{0.000} \\
\hline & Environmental mastery & -0.096 & -0.073 & -1.054 & 0.293 & & & & \\
\hline & Personal growth & -0.024 & -0.017 & -0.248 & 0.805 & & & & \\
\hline & Positive relation with others & -0.248 & -0.210 & -3.125 & 0.002 & & & & \\
\hline & Purposefulness in life & -0.257 & -0.210 & -3.559 & 0.000 & & & & \\
\hline & Self- acceptance & 0.052 & 0.040 & 0.690 & 0.491 & & & & \\
\hline \multirow{7}{*}{ Self- defeating style } & Fixed & 7.170 & & 11.107 & 0.000 & \multirow{7}{*}{0.441} & \multirow{7}{*}{0.194} & \multirow{7}{*}{10.580} & \multirow{7}{*}{0.000} \\
\hline & Autonomy & -0.141 & -0.113 & -1.685 & 0.093 & & & & \\
\hline & Environmental mastery & -0.134 & -0.097 & -1.433 & 0.153 & & & & \\
\hline & Personal growth & -0.033 & -0.023 & -0.361 & 0.736 & & & & \\
\hline & Positive relation with others & -0.333 & -0.269 & -4.653 & 0.000 & & & & \\
\hline & Purposefulness in life & -0.261 & -0.204 & -3.101 & 0.002 & & & & \\
\hline & Self- acceptance & 0.042 & 0.031 & 0.546 & 0.585 & & & & \\
\hline
\end{tabular}

With regard to the results presented in table 4 , it can be said that from among dimensions of psychological well- being, only two dimensions of positive relation with others and purposefulness in life can predict the humor styles $(\mathrm{P} \leq 0.05 ; \mathrm{t} \geq$ 1.96); while the results indicate that among dimensions of psychological well- being, four dimensions of autonomy, environmental mastery, personal growth and self- acceptance have not been recognized as the predictor of humor styles $(\mathrm{P}>0.05 ; \mathrm{t}<1.96)$. The results of multi- regression analysis reveal that the relationship between two dimensions of positive relation with others and purposefulness in life with two affiliative and self- enhancing styles is positive and their relationship with two aggressive and self- defeating styles is reverse and negative; in such a way that two dimensions of positive relation with others and purposefulness in life in interaction with each other respectively with the regression coefficients $0.41,0.47,0.40$ and 0.44 predict respectively about $\% 17, \% 22, \% 16$ and $\% 19$ of the variance of affiliative, self- enhancing, aggressive and self- defeating styles.

Table 5. Summary of linear sample regression coefficients of attitude toward suicide and its dimensions based on psychological well-being.

\begin{tabular}{llllllll}
\hline Predictor variable & Criterion variable & $\mathbf{B}$ & $\mathbf{R}$ & $\mathbf{R}^{2}$ & $\mathbf{t}$ & $\mathbf{F}$ & $\mathbf{p}$ - value \\
\hline & Life attraction & 1.267 & 0.434 & 0.189 & 7.893 & 62.307 & 0.000 \\
Psychological well- & Life non- acceptance & -0.923 & 0.324 & 0.105 & -5.601 & 31.371 & 0.000 \\
being & Death attraction & -1.00 & 0.352 & 0.124 & -6.160 & 37.946 & 0.000 \\
& Death non- acceptance & 0.669 & 0.236 & 0.056 & 3.984 & 15.876 & 0.000 \\
& Total score of attitude toward suicide & -0.494 & 0.340 & 0.116 & -5.927 & 35.124 & 0.000 \\
\hline
\end{tabular}

As it is observed in table 5, the effect of psychological wellbeing on the attitude toward suicide and its four dimensions is meaningful. With regard to the findings, the effect of wellbeing on two dimensions of life attraction and death nonacceptance is positive and its effect on the total score of attitude toward suicide and two dimensions of life nonacceptance and death attraction is reverse (negative) $(\mathrm{P} \leq 0.05$; $t \geq 1.96$ ); in such a way that it can be said: the psychological well- being with regression coefficients of $0.43,0.32,0.35$, 0.24 and 0.34 specifies respectively about $19,11,12,7$ and 12 percent of the variance of life attraction, life non- acceptance, death attraction, death non- acceptance and total score of attitude toward suicide. 
Table 6. Summary of multi regression coefficients of attitude toward suicide and its dimensions based on psychological well- being dimensions.

\begin{tabular}{|c|c|c|c|c|c|c|c|c|c|}
\hline Criterion variable & Predictor variable & $\mathbf{Y}$ & Beta & $\mathbf{T}$ & p-value & $\mathbf{R}$ & $\mathbf{R}^{2}$ & $\mathbf{F}$ & p-value \\
\hline \multirow{6}{*}{ Life attraction } & Fixed & 0.261 & & 0.475 & 0.635 & \multirow{6}{*}{0.627} & \multirow{6}{*}{0.394} & \multirow{6}{*}{28.459} & \multirow{6}{*}{0.000} \\
\hline & Autonomy & 0.000 & 0.000 & -0.002 & 0.999 & & & & \\
\hline & Environmental mastery & 0.023 & 0.017 & 0.283 & 0.777 & & & & \\
\hline & Personal growth & 0.020 & 0.014 & 0.234 & 0.815 & & & & \\
\hline & Positive relation with others & 0.679 & 0.559 & 11.153 & 0.000 & & & & \\
\hline & Purposefulness in life & 0.211 & 0.168 & 2.937 & 0.004 & & & & \\
\hline \multirow{7}{*}{ Life non- acceptance } & Fixed & 4.908 & & 8.527 & 0.000 & \multirow{7}{*}{0.552} & \multirow{7}{*}{0.304} & \multirow{7}{*}{19.178} & \multirow{7}{*}{0.000} \\
\hline & Autonomy & 0.063 & 0.053 & 0.846 & 0.398 & & & & \\
\hline & Environmental mastery & 0.004 & 0.003 & 0.052 & 0.958 & & & & \\
\hline & Personal growth & 0.086 & 0.063 & 0.979 & 0.329 & & & & \\
\hline & Positive relation with others & -0.592 & -0.499 & -9.295 & 0.000 & & & & \\
\hline & Purposefulness in life & -0.178 & -0.145 & -2.375 & 0.018 & & & & \\
\hline & Self- acceptance & 0.019 & 0.015 & 0.274 & 0.784 & & & & \\
\hline \multirow{6}{*}{ Death attraction } & Autonomy & -0.0012 & -0.010 & -0.155 & 0.877 & \multirow{6}{*}{0.458} & \multirow{6}{*}{0.210} & \multirow{6}{*}{11.633} & \multirow{6}{*}{0.000} \\
\hline & Environmental mastery & -0.111 & -0.084 & -0.2501 & 0.212 & & & & \\
\hline & Personal growth & -0.074 & -0.054 & -0.796 & 0.426 & & & & \\
\hline & Positive relation with others & -0.470 & -0.397 & -6.940 & 0.000 & & & & \\
\hline & Purposefulness in life & -0.161 & -0.132 & -2.039 & 0.042 & & & & \\
\hline & Self- acceptance & -0.086 & -0.066 & -1.170 & 0.243 & & & & \\
\hline \multirow{7}{*}{ Death non- acceptance } & Fixed & 1.331 & & 2.280 & 0.032 & \multirow{7}{*}{0.522} & \multirow{7}{*}{0.273} & \multirow{7}{*}{16.442} & \multirow{7}{*}{0.000} \\
\hline & Autonomy & -0.111 & $-0 / 094$ & -1.475 & 0.142 & & & & \\
\hline & Environmental mastery & -0.069 & -0.052 & -0.813 & 0.417 & & & & \\
\hline & Personal growth & 0.066 & 0.048 & 0.737 & 0.462 & & & & \\
\hline & Positive relation with others & 0.520 & 0.441 & 8.042 & 0.000 & & & & \\
\hline & Purposefulness in life & 0.240 & 0.197 & 3.154 & 0.002 & & & & \\
\hline & Self - acceptance & -0.062 & -0.048 & -0.887 & 0.376 & & & & \\
\hline \multirow{5}{*}{$\begin{array}{l}\text { Total score of attitude } \\
\text { toward suicide }\end{array}$} & Environmental mastery & -0.010 & -0.015 & -0.238 & 0.812 & \multirow{5}{*}{0.547} & \multirow{5}{*}{0.299} & \multirow{5}{*}{18.673} & \multirow{5}{*}{0.000} \\
\hline & Personal growth & -0.053 & -0.076 & -1.181 & 0.239 & & & & \\
\hline & Positive relation with others & -0.210888 & -0.475 & -8.823 & 0.000 & & & & \\
\hline & Purposefulness in life & -0.116 & -0.186 & -3.031 & 0.003 & & & & \\
\hline & Self- acceptance & -0.033 & -0.050 & -0.942 & 0,347 & & & & \\
\hline
\end{tabular}

According to the results presented in table 6, it can be said that from among the psychological well- being dimensions, only two dimensions of positive relation with others and purposefulness in life can predict the attitude toward suicide and its dimensions $(\mathrm{P} \leq 0.05 ; \mathrm{t} \geq 1.96)$, while the results show that from among psychological well- being dimensions, four dimensions of autonomy, environmental mastery, personal growth and self- acceptance have not been recognized as the predictor of attitude toward suicide and its dimensions $(\mathrm{P}>$ $0.05 ; \mathrm{t}<1.96)$. The results of multi regression analysis indicates that the relationship between two dimensions of positive relation with others and purposefulness in life with two dimensions of life attraction and death non- acceptance is positive and their relationship with total score of attitude toward suicide and two dimensions of death attraction and life non- acceptance is reverse and negative; in such a way that two dimensions of positive relation with others and purposefulness in life in interaction with each other respectively with regression coefficients of $0.63,0.55,0.46$, 0.52 and 0.55 predict respectively $39,30,21,27$ and 30 percent of the variance of life attraction, life non- acceptance, death attraction, death non- acceptance and total score of attitude toward suicide.

\section{Discussion}

The present research was accomplished with the aim of studying the relationship between the humor styles and attitude toward suicide with the psychological well- being in the teenager. The findings of present research revealed that from among the psychological well- being dimensions, only two dimensions of positive relation with others and purposefulness in life can predict the humor styles. From among the psychological wellbeing dimensions, only these two dimensions can predict the attitude toward suicide and its dimensions. According to research results, if the individual have more aggressive and self- defeating humor, his/ her tendency toward the suicide and the possibility of increase of motivation for suicide would be increased. Furthermore, the data analysis revealed that the psychological well- being has relationship with the humor styles and attitude toward suicide styles.

The results of this research with the research of [19-26] Is 
aligned.

The direct relationship between the connecting style and the problem-oriented style and the self-increasing style with the emotion-oriented style leads to the adjustment of emotional helplessness and the reduction of the severity of the stressful situation cognitively, thus reducing the attitude towards suicide. Therefore, first of all, breeding and paying attention to these relationships should be considered. As psychologists, psychotherapists, and counselors, especially in schools, as an effective social institution, it is best to lead adolescents into positive moods in order to increase their life expectancy and negative attitudes toward suicide and attraction to life. Increase in them.

According to the results, it is recommended that adequate education be provided to increase the use of positive humor styles in order to reduce the positive attitude towards suicide in adolescents and increase their happiness and psychological well-being; Because prevention is better than cure. Programs can be established to raise people's awareness to enhance their mental health by increasing and strengthening their sense of humor. Humor is a tool for feeling mentally and physically healthy. Having a sense of humor reduces the symptoms of anxiety and depression and increases social functioning. A person with a sense of humor shows a higher level of daily functioning, social functioning and emotion. The higher the level of humor, the better the person has mental health and social functions. However, this study can indicate the importance of humor and suicidal ideation in psychological well-being in adolescents.

The research results can be a guidance for the consulting and psychotherapy centers of education research centers, welfare organization and education department.

\section{Notes}

Note 1. This is an example.

Note 2. This is an example for note 2 .

\section{Appendix}

The Heading to Appendix A

In general, an appendix is appropriate for materials that are relatively brief and that are easily presented in print format. Some examples of material suitable for an appendix are (a) a list of stimulus materials (e.g., those used in psycholinguistic research), (b) a detailed description of a complex piece of equipment, (c) a list of articles that provided the source data for a meta-analysis but are not directly referred to in any other way in an article, and (d) a detailed demographic description of subpopulations in the study and other detailed and/or complex reporting items suggested in the reporting standards section of this chapter.

If your manuscript has only one appendix, label it Appendix; if your manuscript has more than one appendix, label each one with a capital letter (Appendix A, Appendix B, etc.) in the order in which it is mentioned in the main text. Each appendix must have a title. In the text, refer to appendices by their labels: produced the same results for both studies (see Appendices A and $\mathrm{B}$ for complete proofs).

\section{Copyrights}

Copyright for this article is retained by the author (s), with first publication rights granted to the journal.

This is an open-access article distributed under the terms and conditions of the Creative Commons Attribution license (http://creativecommons.org/licenses/by/3.0/).

\section{References}

[1] Spirito A, Overholser J, Hart K. (1991). Cognitive characteristics of adolescent suicide attempters. J angloam acad Child \& Adolesc Psychiatry. 30 (4): 604-8.

[2] WHO. (2017). World Health OrganizationSuicide: Fact Sheet. Retrieved from http://www.who.int/mediacentre/factsheets/fs398/en/.

[3] Wasserman, D., \& Wasserman, C. (Eds.). (2009). Oxford textbook of suicidology and suicide prevention. OUP Oxford.

[4] Akotia, C. S., Knizek, B. L., Hjelmeland, H., Kinyanda, E., \& Osafo, J. (2019). Reasons for attempting suicide: An exploratory study inGhana. Transcultural psychiatry, 56 (1), 233-249. doi: $10.1177 \% 2$ F1363461518802966.

[5] Morales-Vives, F., \& Dueñas, J. M. (2018). Predicting suicidal ideation in adolescent boys and girls: the role of psychological maturity, personality traits, depression and life satisfaction. The Spanish journal of psychology, 21, E10. doi: 10.1017/sjp.2018.12.

[6] Diekstra, R. F. W. (1973). Crisis en gedragskeuze: een theoretische en empirische bijdrage tot het zelfmoordprobleem (Doctoral dissertation, Meppel: Krips Repro).

[7] Cong, E. Z., Wu, Y., Cai, Y. Y., Chen, H. Y., \& Xu, Y. F. (2019). Association of suicidal ideation with family environment and psychological resilience in adolescents. Zhongguo dang dai er ke za zhi= Chinese journal of contemporary pediatrics, 21 (5), 479-484.

[8] Bahadori Khosroshahi, J, Khanjani, Z, (2011), The Relationship between Humor and Life Stressful Events with Depression in Students, Zahedan Journal of Medical Sciences Research, (2) 14, 100-96.

[9] Martin, R. A. (1998). Approaches to the sense of humor: A historical review. in ruch(ed). The sense of humor p, 15-60.

[10] Martin, R. A., Puhilk, P, Larsen, G. J, \& Weir, K. (2003). Indhvhdual difference in uses of humor and their relation to psychological well- being, jornal of research in personality, 37 , 48-57.

[11] Lyubomirsky, S., \& Lepper, H. S. (1999). A measure of subjective happiness: Preliminary reliability and construct validation. Social indicators research, 46 (2), 137-155.

[12] Rees, G., \& Bradshaw, J. (2018). Exploring low subjective well-being among children aged 11 in the UK: an analysis using data reported by parents and by children. Child Indicators Research, 11 (1), 27-56. 
[13] Shek, D. T. (1997). Family environment and adolescent psychological well-being, school adjustment, and problem behavior: A pioneer study in a Chinese context. The Journal of Genetic Psychology, $158 \quad$ (1), 113-128. doi: $10.1080 / 00221329709596656$.

[14] Abrutyn, S., Mueller, A. S. (2014). Are suicidal behaviors contagious in adolescence? Using longitudinal data to examine suicide suggestion. American Sociological Review, 79, 211227. https://doi.org/10.1177/0003122413519445.

[15] Randall, J. R., Nickel, N. C., Colman, I. (2015). Contagion from peer suicidal behaviour in a representative sample of American adolescents. Journal of Affective Disorders, 186, 219-225. Doi: 10.1016/j.jad.2015.07.001.

[16] Kasser, T., Rosenblum, K. L., Sameroff, A. J., Deci, E. L., Niemiec, C. P., Ryan, R. M.,.. \& Hawks, S. (2014). Changes in materialism, changes in psychological well-being: Evidence from three longitudinal studies and an intervention experiment. Motivation and Emotion, 38 (1), 1-22.

[17] Van Ryzin, M. J., Gravely, A. A., \& Roseth, C. J. (2009) Autonomy, belongingness, and engagement in school as contributors to adolescent psychological well-being. Journal of $\begin{array}{llll}\text { youth and } & \text { adolescence, } 38 \text { (1), }\end{array}$ https://link.springer.com/article/10.1007/s10964-007-9257-4.

[18] Wong, F. K. D., Chang, Y. L., \& He, X. S. (2009). Correlates of psychological wellbeing of children of migrant workers in Shanghai, China. Social psychiatry and psychiatric epidemiology, $\quad 44 \quad$ (10), 815-824. https://link.springer.com/article/10.1007/s00127-009-0003-y.

[19] Arslan, G. (2018). Psychological maltreatment, social acceptance, social connectedness, and subjective well-being in adolescents. Journal of Happiness Studies, 19 (4), 983-1001.

[20] Becker, M. A. S., Schelbe, L., Romano, K., \& Spinelli, C. (2017). Promoting First-Generation College Students' Mental Well-Being: Student Perceptions of an Academic Enrichment Program. Journal of College Student Development, 58 (8), 1166-1183.

[21] Gulbas, L. E., Guz, S., Hausmann-Stabile, C., Szlyk, H. S., \& Zayas, L. H. (2019). Trajectories of well-being among Latina adolescents who attempt suicide: a longitudinal qualitative analysis. Qualitative health research, 28. doi: $10.1177 / 1049732319837541$.

[22] Khanipoor, H, (2015), Self-harm behaviors in adolescents: The nature, probability of suicide and the role of psychological factors and peers, Doctoral dissertation in psychology, Allameh Tabataba'i University.
[23] Mattew, K. N. (2008) About teen suicide. http//www.app.org (American Academy of chid \& Adolescent Psychiatry).

[24] Platt, T., Gander, F., \& Giuliani, F. (2019). Relationships of retrospectively assessed class clown behavior with current humor and well-being. Current Psychology. doi: 10.1007/s12144-019-00571-9.

[25] Poor Sharifi, H, Habibi, M, Zarani, F, Ashouri, A, Hafezi, M, Hajibi, A, Boohari, J; (2012), The Role of Depression, Stress, Happiness, and Social Support in Identifying Students' Suicidal Thoughts, Journal of Psychological Psychology Iranian Clinical Oncology, (2) 18, 107-99.

[26] Reyes-Portillo, J. A., Lake, A. M., Kleinman, M., \& Gould, M. S. (2019). The relation between descriptive norms, suicide ideation, and suicide attempts among adolescents. Suicide and Life-Threatening Behavior, 49 (2), 535-546.

[27] Kaplan-Sadok, (2009), Summary of Psychiatry, Volume Three, Translated by: Nosratollah Pur Afkari, Tehran; Water City Publications.

[28] Keyes, C. L., \& Lopez, S. J. (2009). Toward a science of mental health. In: S. J. Lopez and C. R. Cynder (Eds.), Oxford handbook of positive psychology. New York: Oxford University Press.

[29] Armsden, G. C., \& Greenberg, M. T. (1987). The inventory of parent and peer attachment: Individual differences and their relationship to psychological well-being in adolescence. Journal of youth and adolescence, 16 (5), 427-454.

[30] Sarmad, Z; Hejazi, A., Bazargan, A., (2011), Management Education in Care Sciences, Tehran: Agha Publications.

[31] Zare, H., Kamali Zarch, M., Rezaei Nasab, F., (2009), Humorous styles and five personality traits, Iranian Journal of Psychology, (22) 6, 127-119.

[32] Orbach, I., Milstein, I., Har-Even, D., Apter, A. Tiano, S. Elizur, A. (1981). A Multi-Attitude Suicide Tendency Scale for adolescents, Psychological Assessment, 3, 398-404.

[33] Ryff, C. D. (1989). Happiness is everything, or is it? Exploration on the meaning of psychological wellbeing. Journal of Personality and Social Psychology, 57, 1069-1081.

[34] Martin, R. A., Puhlik-doris, P., Larsen, G., Gray, J., \& Weir, K. (2003). Individual differences in uses of humor and their relation to psychological well-being: Development of the humor styles questionnaire. Journal of Research in Personality, $37,48-75$. 